\title{
Differences in Quality of Life Between Men and Women who Undergo Bladder Preservation with Trimodality Therapy
}

\author{
Leslie K. Ballas ${ }^{\mathrm{a}, *}$, Andrzej Niemierko ${ }^{\mathrm{b}}$, Kimberley S. Mak ${ }^{\mathrm{c}}$, \\ Michael Drumm ${ }^{\mathrm{d}}$ and Jason A. Efstathiou ${ }^{\mathrm{b}}$ \\ ${ }^{a}$ Department of Radiation Oncology, University of Southern California Keck School of Medicine, Los Angeles, \\ CA, USA \\ ${ }^{\mathrm{b}}$ Department of Radiation Oncology, Massachusetts General Hospital, Harvard Medical School, Boston, MA, \\ USA \\ ${ }^{\mathrm{c}}$ Department of Radiation Oncology, Boston Medical Center, Boston University School of Medicine, Boston, \\ MA, USA \\ ${ }^{\mathrm{d}}$ Feinberg School of Medicine, Northwestern University, Chicago, IL, USA
}

Received 1 February 2021

Accepted 21 April 2021

Pre-press 11 May 2021

Published 31 August 2021

\begin{abstract}
.
PURPOSE: Sex-specific differences exist in muscle invasive bladder cancer (MIBC): men have a higher incidence; women present with more advanced disease; and surgical options differ between men and women. Health related quality of life (HRQoL) for male versus female patients with MIBC is not well understood and limited data exists in patients who undergo bladder preservation with trimodality therapy (TMT). The purpose of this study was to compare long-term HRQoL between men and women who have undergone TMT.

METHODS AND MATERIALS: This was a secondary analysis of a prior study that reported long-term HRQoL differences for patients who underwent TMT. We analyzed patient reported HRQoL data to assess differences in HRQoL between men and women.

RESULTS: Of the 64/74 (86\%) TMT patients that completed questionnaires, $14(22 \%)$ were women. Median age at diagnosis was 60 years for women and 66 years for men $(p=0.007)$. From six HRQoL instruments, there were two responses with a statistically significant difference between women and men - incidence of diarrhea and degree of sexual activity. Fifty percent of women compared to $86 \%$ of men reported no diarrhea $(p=0.02)$. A greater percentage of women reported some degree of sexual activity in the 4 weeks prior to questionnaire completion $(p=0.04)$, and sexual interest following TMT declined significantly with age in men, but not in women.

CONCLUSIONS: In general, men and women report very good long-term HRQoL following TMT. There were, however, some differences between the sexes. Understanding this difference, especially related to sexual function, will allow more informed decision making by patients when choosing between treatment modalities.
\end{abstract}

Keywords: Bladder cancer, MIBC, Trimodality therapy, bladder preservation, radiotherapy

${ }^{*}$ Correspondence to: Leslie K. Ballas, MD; University of Southern California Keck School of Medicine, Department of Radiation Oncology, 1441 Eastlake Ave, Norris G350. Los Ange- les, CA 90033, USA. Tel.: +1 323865 3050; Fax: +1 323865 0000; E-mail: LBALLAS@MED.USC.EDU. 


\section{INTRODUCTION}

The incidence of bladder cancer is about four times higher in men than in women [1]. Sex-based disparities in the timeliness and thoroughness of diagnostic evaluation of muscle invasive bladder cancer (MIBC) creates delays for women [2,3] that can lead to higher risk of cancer-specific mortality [4], and may contribute to women presenting with more advanced stage disease. Health-related quality of life (HRQoL) is important for cancer survivors. In the MIBC setting, when patients decide between radical cystectomy (RC) and bladder sparing trimodality therapy (TMT) [5], HRQoL can be crucial to understanding future functional independence, social and emotional health, sexual function and body image [6]. Sex-specific HRQoL among women undergoing RC has been reported [6-8], most typically comparing different types of urinary diversion following RC.

For patients choosing TMT, HRQoL data is more limited than for RC. Huddart, et al. reported prospective HRQoL data from the BC2001 trial using the Functional Assessment of Cancer Therapy - Bladder Cancer (FACT-BL) questionnaire [9]. Mak, et al. reported long-term HRQoL comparing RC to TMT using 6 validated questionnaires [10]. Neither study compared HRQoL to assess sex-specific differences. The purpose of this study was to compare long-term HRQoL in men versus women in a cohort of TMT patients.

\section{METHODS}

A prior institutional review board approved crosssectional HRQoL study evaluated 173 patients with nonmetastatic cT2-cT4 MIBC, diagnosed between 1990 to 2011, who underwent RC or TMT and were disease free for $\geq 2$ years following treatment [10]. Patients were mailed introductory letters from their radiation oncologist outlining the purpose, risks, benefits and voluntary nature of the study, and implied consent was given based on return of completed questionnaires. These patients answered six validated HRQoL instruments: EuroQOL EQ-5D, European Organisation for Research and Treatment of Cancer (EORTC) Quality of Life Core Questionnaire (QLQC30) and EORTC MIBC module (QLQ-BLM30), Expanded Prostate Cancer Index Composite (EPIC) bowel scale, the items addressing cancer control, informed decision making, and regret from Cancer

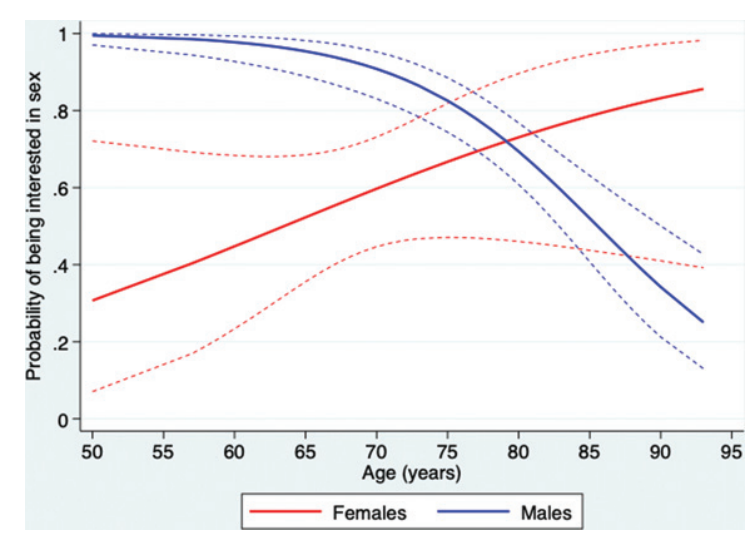

Fig. 1. Probability of being interested in sex as a function of age (dashed lines are 95\% confidence intervals) for women and men following TMT.

Treatment and Perception Scale (CTPS), and Impact of Cancer, version 2 (IOCv2). Instruments were scaled to $0-100$ scores per published scoring instructions.

In this retrospective secondary analysis, only the 74 TMT patients were analyzed for sex-based differences in HRQoL. The two-sample Wilcoxon rank-sum test was used to compare HRQoL score distributions. To allow for the effect of age on sexual interest, sexual scores were dichotomized into 'yes' and 'no' and compared using multivariable logistic regression with age and gender as covariates. This was then graphed to show the probability of being interested in sex as a function of age (Fig. 1). All $P$-values were two-tailed and $p<0.05$ was considered statistically significant. Stata (StataCorp 2019, release 16) was used for all analyses.

\section{RESULTS}

Of the 64/74 (86\%) TMT patients that completed questionnaires, 14 (22\%) were women. Median age at diagnosis was 60 years for women and 66 years for men $(p=0.007)$. As previously reported, the median follow-up from diagnosis to questionnaire completion in the TMT cohort was 9 years (IQR 5.25 -12.60 years) [10]. The median age at questionnaire completion for women versus men was 70 and 78, respectively $(p=0.02)$. The median RT dose was $64.3 \mathrm{~Gy}$ with $97 \%$ of patients receiving concurrent chemotherapy. All patients were treated with $3 \mathrm{D}$ conformal radiotherapy except one, who was treated with intensity modulated radiotherapy (IMRT) in June 2010. 
Table 1

Sexual and Diarrhea HRQoL in Women vs Men who undergo TMT from EORTC BLM-30

\begin{tabular}{|c|c|c|c|c|c|c|c|c|c|}
\hline & \multicolumn{4}{|c|}{ Female, number respondents (\%) } & \multicolumn{4}{|c|}{ Male, number respondents (\%) } & \multirow[t]{2}{*}{$p$-value } \\
\hline & $\begin{array}{l}\text { Not at } \\
\text { all }\end{array}$ & $\begin{array}{c}\text { A } \\
\text { little }\end{array}$ & $\begin{array}{l}\text { Quite } \\
\text { a bit }\end{array}$ & $\begin{array}{l}\text { Very } \\
\text { much }\end{array}$ & $\begin{array}{l}\text { Not at } \\
\text { all }\end{array}$ & $\begin{array}{c}\text { A } \\
\text { little }\end{array}$ & $\begin{array}{l}\text { Quite } \\
\text { a bit }\end{array}$ & $\begin{array}{l}\text { Very } \\
\text { much }\end{array}$ & \\
\hline \multicolumn{10}{|l|}{$\begin{array}{l}\text { EORTC QLQ-BLM30 Items for } \\
\text { patients who were sexually active } \\
\text { in the past } 4 \text { weeks }\end{array}$} \\
\hline $\begin{array}{l}\text { To what extent were you interested in } \\
\text { sex? }\end{array}$ & $5(41.7)$ & $4(33.3)$ & $3(25)$ & 0 & $12(24.5)$ & $21(42.9)$ & $14(28.6)$ & $2(4.1)$ & 0.6 \\
\hline $\begin{array}{l}\text { To what extent were you sexually } \\
\text { active? }\end{array}$ & $5(41.7)$ & $6(50)$ & 0 & $1(8.3)$ & $29(60.4)$ & $12(25)$ & $7(14.6)$ & 0 & 0.04 \\
\hline $\begin{array}{l}\text { FOR MEN ONLY: Did you have } \\
\text { difficulty gaining or maintaining an } \\
\text { erection? }\end{array}$ & 0 & 0 & 0 & 0 & $8(18.2)$ & $13(29.6)$ & $3(6.8)$ & $20(45.5)$ & \\
\hline $\begin{array}{l}\text { FOR MEN ONLY: Did you have } \\
\text { ejaculation problems (e.g. dry } \\
\text { ejaculation)? }\end{array}$ & 0 & 0 & 0 & 0 & $16(39)$ & $8(19.5)$ & $5(12.2)$ & $12(29.3)$ & \\
\hline $\begin{array}{l}\text { Have you felt uncomfortable about } \\
\text { being sexually intimate? }\end{array}$ & $4(80)$ & $1(20)$ & 0 & 0 & $12(80)$ & $2(13.3)$ & $1(6.7)$ & 0 & 0.8 \\
\hline $\begin{array}{l}\text { Have you worried that you may } \\
\text { contaminate your partner during } \\
\text { sexual contact with the bladder } \\
\text { treatment you have been receiving? }\end{array}$ & $6(100)$ & 0 & 0 & 0 & $14(93.3)$ & $1(6.7)$ & 0 & 0 & 0.5 \\
\hline $\begin{array}{l}\text { To what extent was sex enjoyable for } \\
\text { you? }\end{array}$ & $1(20)$ & 0 & $4(80)$ & 0 & $1(6.7)$ & $1(6.7)$ & $11(73.3)$ & $2(13.3)$ & 0.64 \\
\hline $\begin{array}{l}\text { Women: Did you have a dry vagina or } \\
\text { other problems during intercourse }\end{array}$ & $4(80)$ & 0 & $1(20)$ & 0 & 0 & 0 & 0 & 0 & \\
\hline \multicolumn{10}{|l|}{ EORTC QLQ-BLM30 Diarrhea } \\
\hline $\begin{array}{l}\text { During the past week have you had } \\
\text { diarrhea? }\end{array}$ & $7(50)$ & $6(42.9)$ & $1(7.1)$ & 0 & $42(85.7)$ & $6(12.2)$ & $1(2)$ & 0 & 0.02 \\
\hline
\end{tabular}

\section{General HRQoL}

From the general HRQoL instruments (EORTC QLQ-C30 and EQ-5D), only diarrhea (EORTC QLQC30) reached a statistical difference between sexes $(p=0.02)$. Fifty percent of women compared to $86 \%$ of men reported no diarrhea (Table 1). There were no differences reported in emotional, social, cognitive, or role functioning. There were also no differences in HRQoL based on time from diagnosis to questionnaire completion.

\section{Sexual HRQoL}

Of the six questionnaires, only the EORTCBLM30 included items addressing sexual function. The eight items that address sexuality are reproduced in Table 1. Of the 14 female patients, 12 answered items regarding interest in sex and whether they were sexually active. Seven females were sexually active during the 4 weeks prior to questionnaire completion. 'To what extent were you sexually active?' was the only item that demonstrated a statistically significant difference between men and women $(p=0.04)$. Men reported having decreased sexual activity.
When the variable 'to what extent were you interested in sex?' was dichotomized into a binary response of 'yes, interested in sex' or 'no, not interested in sex', and adjusted for age, there was a statistically significant difference between men and women with age affecting the sexes differently. Figure 1 shows that for males, interest in sex decreased significantly with age. Because of fewer female responses to this question, we cannot reject the hypothesis that interest in sex doesn't depend on age for female patients. (as indicated by $95 \%$ confidence intervals).

\section{DISCUSSION}

The Mak et al. study used six validated questionnaires to evaluate $\mathrm{HRQ} \mathrm{OL}$ following $\mathrm{RC}$ and TMT. The questionnaires addressed general, diseasespecific, and impact of disease on HRQoL. There are two commonly used bladder cancer specific instruments: the EORTC BLM-30 and the FACT-BL. The EORTC BLM-30 has 8 items addressing sexual function ( 2 are male specific, 1 female specific). The FACT-BL includes only 2 items on sexuality and asks one male-specific item (about erectile function). 
There are very few reports of sex-specific functional outcomes for MIBC patients, and the minority include standardized instruments to assess female sexual function (partnered or unpartnered) [6]. In order to counsel women on treatment choices, sexual HRQoL should be better understood.

We found two items with statistically significant differences between men and women long-term bladder cancer survivors following TMT: diarrhea and extent of sexual activity. Women reported diarrhea more frequently than men and were more sexually active during the 4 weeks prior to questionnaire completion. Anatomic variations in women may describe the differences in reported diarrhea. By the age of 60 , more than $1 / 3$ of women have had hysterectomy [11] (hysterectomy status on patients in this study is unknown), thus their small bowel may be at greater risk of exposure to radiotherapy. Careful attention to small bowel dose is essential in all patients, and perhaps more so in women. Volumetric dose constraints and organ-sparing radiation planning techniques that are used in modern radiotherapy delivery, such as IMRT, could help mitigate long-term bowel toxicity.

In the TMT population, sexual HRQoL of women has only been specifically mentioned in two studies, both of which evaluated women treated before 1995 $[7,12]$. One evaluated 10 women, with median age of 81 years, all of whom reported no or low interest in sex and none of whom were sexually active during the study period [7]. The other study evaluated 21 women with a median age of 69 years in which only 5 women reported being sexually active; of these 5,2 had increased frequency of sexual activity and $1 \mathrm{had}$ decreased frequency. None of the 5 women reported changes in satisfaction from sex, orgasm or dyspareunia [12].

With limited data on female sexual functioning following TMT, one can try to extrapolate from other disease sites in which external beam pelvic RT is used, including endometrial, rectal and anal cancers. Pelvic RT to lower doses, on average, in these diseases have had late effects on sexual function including dyspareunia, decreased desire, and vaginal dryness [13-19]. Important to note is that patients with MIBC present about a decade older than patients with endometrial, anal or rectal cancers. This difference in age complicates extrapolation of data on sexual functioning.

We found that the median age at diagnosis was 60 years for women and 66 years for men $(p=$ $0.007)$. This is slightly different from what has been reported in the SEER database in which women are slightly older than men at diagnosis (73 years vs 72 years, respectively) [20,21]. The average age of female respondents in this study was 70 years with $7 / 12(58 \%)$ reporting being sexually active during the month that preceded questionnaire completion. Because this study required completed questionnaires to be returned via the mail, there could be selection bias as to what age groups responded.

A study of sexuality and health in older adults estimated $39.5 \%$ of $65-74$-year-old women (the average age of female responders on our study) are sexually active. This same study estimated that $38.5 \%$ of 75-85 year-old men (the average age of male responders in our study) are sexually active [22]. This data implies that the women and men in our study should have reported similar sexual activity levels, but we observed differently. Our differential suggests that other factors are affecting sexual activity, one of which could be sexual interest. We found sexual interest dropped significantly with age in men, but not in women. Whether the link between sexual interest and sexual activity describes the differences between the sexes or whether there may be a treatment effect requires a larger sample size and more specific questionnaires to determine.

Just as we did not find differences in HRQoL based on time from diagnosis to questionnaire completion, Catto, et al. [23], in a recently reported a cross sectional analysis of patient reported outcomes from patients with bladder cancer 1-10 years following diagnosis, did not find a difference in patient reported outcomes based on time from diagnosis. Thus, our patients' responses, completed, on average 9 years following diagnosis, likely represent the HRQoL from all long-term TMT survivors.

Even though to our knowledge, this is the largest analysis of sex-based differences in women compared to men who have undergone TMT, our results are limited because of small sample size. While the limitation exists, it is important to realize that larger sample size is difficult to achieve. In a modern study that prospectively evaluated HRQoL in 452 MIBC patients, responses to questionnaires at 1 year following treatment were captured in 187 men and 40 women [9]. This is the result of the nature of disease progression and the fact that incidence of bladder cancer is 3-4 times greater in men. Another limitation to our study is that it was cross-sectional and no baseline, or pre-TMT, questionnaires were collected. Because all of the questionnaires were validated to ask about HRQoL during the 1-4 weeks preceding questionnaire completion, and do not question 
differences from baseline, having pre-treatment HRQoL data (especially in an elderly population) would be essential for future prospective studies. Additionally, the current commonly used validated questionnaires do not adequately address sexual HRQoL (partnered/unpartnered) and we believe it would be helpful to include sexual HRQoL specific questionnaires in future prospective studies.

\section{CONCLUSIONS}

Treatment-related quality of life impacts patient decision making. While TMT is generally well tolerated in both men and women, there are long-term QoL differences reported by the sexes, especially related to incidence of diarrhea and level of sexual function. To better understand this, future MIBC studies should include prospectively collected HRQoL questionnaires that address female sexuality.

\section{ACKNOWLEDGMENTS}

All authors have contributed to the work in a significant manner, have completed a conflict of interest disclosure and have no conflicts of interest that pertain to this study. There was no external funding that supported this trial.

All data generated and analyzed during this study are included in this published article (and its supplementary information files). Research data are stored in an institutional repository and will be shared upon request to the corresponding author.

\section{FUNDING}

No external funding supported this work.

\section{AUTHORS CONTRIBUTIONS}

Leslie Ballas: conception, interpretation of data, manuscript writing and editing. Andrzej Niemierko: analysis and interpretation of data, editing of manuscript. Kimberley Mak: interpretation of data and editing of manuscript. Michael Drumm: analysis of data. Jason Efstathiou: conception, interpretation of data, editing of manuscript, supervision and administrative support. All authors have had access to the data.

\section{ETHICAL CONSIDERATIONS}

This study is a secondary analysis of a study performed at Massachusetts General Hospital IRB\# 2002P000380. Patients were mailed an introductory letter from their radiation oncologist along with questionnaires and a pre-stamped return envelope. Implied consent procedures were used through return of a completed questionnaire in conjunction with the introductory letter that explained, risks, benefits and voluntary nature of the study.

\section{CONFLICT OF INTEREST}

Leslie Ballas: no conflicts of interest to declare. Andrzej Niemierko: no conflicts of interest to declare. Kimberley Mak: no conflicts of interest to declare. Michael Drumm: no conflicts of interest to declare. Jason Efstathiou: personal fees from Blue Earth Diagnostics, Boston Scientific, AstraZeneca, Taris Biomedical, Janssen, Bayer Healthcare, and Roivant Pharma, Myovant Sciences and Merck.

\section{REFERENCES}

[1] Society AC. Key statistics for bladder cancer. Accessed April 23, 2020. https://www.cancer.org/cancer/bladdercancer/about/key-statistics.html

[2] Cohn JA, Vekhter B, Lyttle C, Steinberg GD, Large MC. Sex disparities in diagnosis of bladder cancer after initial presentation with hematuria: a nationwide claims-based investigation. Cancer. 2014;120(4):555-61. doi:10.1002/ cncr.28416

[3] Johnson EK, Daignault S, Zhang Y, Lee CT. Patterns of hematuria referral to urologists: does a gender disparity exist? Urology. 2008;72(3):498-502; discussion 502-3. doi:10.1016/j.urology.2008.01.086

[4] Hollenbeck BK, Dunn RL, Ye Z, et al. Delays in diagnosis and bladder cancer mortality. Cancer. 2010;116(22):523542. doi: $10.1002 /$ cncr. 25310

[5] Witjes JA, Bruins HM, Cathomas R, et al. European Association of Urology Guidelines on Muscle-invasive and Metastatic Bladder Cancer: Summary of the 2020 Guidelines. Eur Urol. 2021;79(1):82-104. doi:10.1016/ j.eururo.2020.03.055

[6] Smith AB, Crowell K, Woods ME, et al. Functional Outcomes Following Radical Cystectomy in Women with Bladder Cancer: A Systematic Review. Eur Urol Focus. 2017;3(1):136-43. doi:10.1016/j.euf.2016.05.005

[7] Henningsohn L, Wijkström H, Dickman PW, Bergmark K, Steineck G. Distressful symptoms after radical radiotherapy for urinary bladder cancer. Radiother Oncol. 2002;62(2):215-25. doi:10.1016/s0167-8140(01)00455-8

[8] Siracusano S, D'Elia C, Cerruto MA, et al. Quality of Life in Patients with Bladder Cancer Undergoing Ileal Conduit: A Comparison of Women. In Vivo. 2018 Jan-Feb 2018;32(1):139-43. doi:10.21873/invivo.11216 
[9] Huddart RA, Hall E, Lewis R, et al. Patient-reported Quality of Life Outcomes in Patients Treated for Muscle-invasive Bladder Cancer with Radiotherapy \pm Chemotherapy in the BC2001 Phase III Randomised Controlled Trial. Eur Urol. 2020;77(2):260-8. doi:10.1016/j.eururo.2019.11.001

[10] Mak KS, Smith AB, Eidelman A, et al. Quality of Life in Long-term Survivors of Muscle-Invasive Bladder Cancer. Int J Radiat Oncol Biol Phys. 2016;96(5):1028-36. doi:10.1016/j.ijrobp.2016.08.023

[11] Network NWsH. Hysterectomy. Accessed June 12, 2020, https://nwhn.org/hysterectomy/

[12] Kachnic LA, Shipley WU, Griffin PP, et al. Combined modality treatment with selective bladder conservation for invasive bladder cancer: long-term tolerance in the female patient. Cancer J Sci Am. 1996;2(2):79-84.

[13] Incrocci L, Jensen PT. Pelvic radiotherapy and sexual function in men and women. J Sex Med. 2013;10(Suppl 1): 53-64. doi:10.1111/jsm.12010

[14] Law E, Kelvin JF, Thom B, et al. Prospective study of vaginal dilator use adherence and efficacy following radiotherapy. Radiother Oncol. 2015;116(1):149-55. doi:10.1016/ j.radonc.2015.06.018

[15] Jensen PT, Froeding LP. Pelvic radiotherapy and sexual function in women. Transl Androl Urol. 2015;4(2):186-205. doi:10.3978/j.issn.2223-4683.2015.04.06

[16] Allal AS, Obradovic M, Laurencet F, et al. Treatment of anal carcinoma in the elderly: feasibility and outcome of radical radiotherapy with or without concomitant chemotherapy.
Cancer. 1999;85(1):26-31. doi:10.1002/(sici)1097-0142 (19990101)85:1<26::aid-cncr4>3.0.co;2-0

[17] Das P, Cantor SB, Parker CL, et al. Long-term quality of life after radiotherapy for the treatment of anal cancer. Cancer. 2010;116(4):822-9. doi:10.1002/cncr.24906

[18] Provencher S, Oehler C, Lavertu S, Jolicoeur M, Fortin B, Donath D. Quality of life and tumor control after short splitcourse chemoradiation for anal canal carcinoma. Radiat Oncol. 2010;5:41. doi:10.1186/1748-717X-5-41

[19] Bregendahl S, Emmertsen KJ, Lindegaard JC, Laurberg S. Urinary and sexual dysfunction in women after resection with and without preoperative radiotherapy for rectal cancer: a population-based cross-sectional study. Colorectal Dis. 2015;17(1):26-37. doi:10.1111/codi.12758

[20] Scosyrev E, Noyes K, Feng C, Messing E. Sex and racial differences in bladder cancer presentation and mortality in the US. Cancer. 2009;115(1):68-74. doi:10.1002/cncr.23986

[21] N H, AM N, M K, et al. SEER Cancer Statistics Review, 1975-2017. https://seer.cancer.gov/csr/1975_2017/

[22] Lindau ST, Schumm LP, Laumann EO, Levinson W, O'Muircheartaigh CA, Waite LJ. A study of sexuality and health among older adults in the United States. N Engl J Med. 2007;357(8):762-74. doi:10.1056/NEJMoa067423

[23] Catto JWF, Downing A, Mason S, et al. Quality of Life After Bladder Cancer: A Cross-sectional Survey of Patientreported Outcomes. Eur Urol. 2021;doi:10.1016/j.eururo. 2021.01 .032 